\title{
Military High Explosives
}

\author{
Jörg Mathieu* and Hans Stucki
}

\begin{abstract}
Military high explosives are safe to handle, have a long shelf life, their energy density is high and the propagation of the explosion (detonation reaction) is very fast. The energetic compounds are combined with polymers and other substances to match the properties as required. To initiate a detonation, a shock wave is needed. This is accomplished with a small quantity of a primary explosive. Modern, extremely insensitive formulations have been developed in most countries to eliminate accidents with ammunition. Apart from insensitive energetic compounds, new inert or energetic binder systems will be introduced to improve the vulnerability. The search for new energetic materials with highest performance characteristics is a never-ending task.
\end{abstract}

Keywords: Energetic binder $\cdot$ Explosives chemistry $\cdot$ Performance $\cdot$ Safety $\cdot$ Vulnerability

\section{Development of Military High Explosives}

\subsection{General Aspects}

The properties of the first known explosives like black powder and dynamite could not fulfill the requirements of use in munitions. Reliability in use and handling, unpredictability and the risk of unwanted explosions as well as the low performance of the detonation was not sufficient.

The ideal military explosive is powerful, safe and easy to handle, can be stockpiled for long periods of time in any climate and is hard to detonate except under precisely specified conditions. It also has to be loaded into shells, bombs and other objects without any difficulties. The energetic compound is normally mixed with binders and additives, so that a suitable production process can deliver the required explosive objects. Primary explosives are responsible that the propagation of an explosion is initiated. Primary explosives are also explained in this article.

\footnotetext{
${ }^{*}$ Correspondence: J. Mathieu

armasuisse

Science and Technology

Feuerwerkerstrasse 39

$\mathrm{CH}-3602$ Thun

Tel.: +41332284464

Fax: +41332284601

E-Mail: joerg.mathieu@armasuisse.ch
}

\subsection{Traditional Military Explosives}

The first high explosive to be put into service was 2,4,6-trinitrophenol, called 'picric acid'. It was first demonstrated in France in 1885 and it was widely used in the time of World War I. Unfavorable are the high melting point, making the process of filling shells difficult, its reaction with heavy metals and formation of toxic compounds and its sensitivity.

The first explosive to fulfill the expectations of producers and users was 2,4,6-trinitrotoluene (TNT). This compound was first synthesized in the $1860 \mathrm{~s}$, was produced in large quantities during World Wars I and II and is still used today in explosive mixtures. It is cheap and relatively insensitive, can be melted at low temperatures and poured in bombs and shells easily.

For higher performance the nitramine compounds hexahydro-1,3,5-trinitro-1,3,5triazine (RDX) and later octahydro-1,3,5,7tetranitro-1,3,5,7-tetrocine (HMX) were introduced. In the pure state these compounds are too sensitive and can only be used with insensitive additives or in mixtures with TNT. In Switzerland, the nitrate ester 2,2bis[(nitroxy)methyl]-1,3-propanediol, dinitrate (PETN) was often used for special applications.

\subsection{Trends and New Products}

The search for new energetic compounds with increased performance is progressing rather slowly. The design of new molecules with a high energy level is fascinating, but the demanded stability is hard to achieve. Manufacturing of blended and polymer-bonded explosives meeting the desired demands such as easy processing and handling together with keeping a high se- curity level is the state-of-the-art. The latest developments try to increase the safety of the explosive products while handling and in case of fire or other unwanted external influences like impact, falling and being fired on.

\section{Primary Explosives and Detonators}

\subsection{General Aspects}

The start of a detonation is normally performed by a primary explosive which produces a detonation wave when decomposed. These compounds have low activation energy. Impact, friction, electric sparks or sudden heating can initiate the decomposition. The deflagration to detonation transition occurs within a very short distance and the detonation wave is sufficient to initiate a secondary explosive in the neighborhood. Because of their sensitivity, primary explosives are manufactured under special conditions to avoid any shock, mechanical load or electric spark. In igniters and detonators only small quantities of primary explosives in the range of $20-100 \mathrm{mg}$ are used.

\subsection{Primary Explosives and Their Properties}

For many years mercury fulminate, $\mathrm{Hg}(\mathrm{ONC})_{2}$, was the compound mainly employed for initiation, either by itself or mixed with other substances such as potassium chlorate. It is easy to prepare by the reaction of mercury with nitric acid and ethanol. Mercury fulminate is toxic, lacks stability when stored for a long time and reacts with metals in a moist atmosphere. Its use has been abandoned in most countries. 
Lead azide, $\mathrm{Pb}\left(\mathrm{N}_{3}\right)_{2}$, was developed after World War I and is now the most commonly used material for detonators. It is produced by the reaction of lead nitrate or acetate with sodium azide in a basic environment, to avoid formation of hydrazoic acid, which is instable. The addition of thickeners like dextrin to the solution, leads to aggregates with purities of only 92$97 \%$, but with good stability and handling safety.

Lead trinitroresorcinate or lead styphnate (Fig. 1) is prepared by the reaction of the magnesium salt of 2,4,6-trinitroresorcinol with lead nitrate. The precipitated lead styphnate is a primary explosive. This compound has good stability, is compatible with most metals, is easy to initiate by impact or heat and is especially sensitive to sparks. It azide in detonators, in electric igniters and in primary compositions to ignite burning.

The main sensitivity and performance properties of widely used primary explosives are listed in Table 1. The corresponding test methods are described by Köhler and Meyer [1]. The figures listed are published data [1] and experimentally determined in our laboratories.

Other compounds used as primary explosives or as a component in primary mixtures are silver azide, tetrazolyl-guanyltetrazene-hydrate (tetrazene) and 2-diazo4,6-dinitrophenol (DDNP).

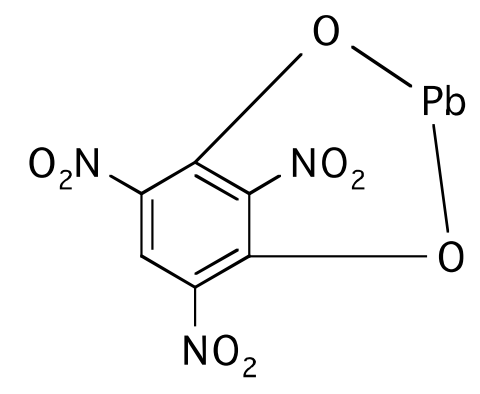

Fig. 1. Lead styphnate is widely used in combination with lead

\subsection{Trends}

Unpredicted explosions, corrosion and erosion of gun barrels and materials, and toxic pollution are the reasons for new improvements in this field. Igniters containing mercury fulminate and chlorates had corrosive as well as toxic properties. The developments in this field led to the primer composition SINOXID containing lead styphnate, tetrazene and inorganic nitrates. This composition has conquered the whole world, it guarantees almost no corrosion and no erosion in the gun, it has excellent stability and storability and ensures precise inflammation of the propellant [2].

With modern target practice in indoor rifle ranges, the lead dust in the air reached intolerably high levels. To eliminate lead and other toxic metals, the SINTOX primary composition without any toxic metals was developed. The primary explosives are 2-diazo-4,6-dinitrophenol and tetrazene combined with the pyrosystem zinc peroxide and titanium.

There is also a trend to develop detonators without primary explosives. The exploding bridge wire initiation delivers an alternative possibility to start a detonation. A metal wire embedded in secondary high explosive material is charged with a very high electrical current. The sudden evaporation of the wire and the resulting shock-wave is sufficient to initiate the surrounding secondary explosive.

An other new method is the direct initiation of secondary explosives by a laser beam.

\section{Secondary Explosives}

\subsection{Energetic Compounds \\ 3.1.1. General Aspects}

Energetic compounds for use as high explosives have to be powerful because their energy is mainly responsible for the performance of an explosive charge. Compatibility and misciability with other explosives, polymers, and additives must be possible, also processes like pressing, melting, cast cure, and extruding are required in the manufacturing process. Compatibility with other materials and long-term stability is

Table 1. Properties of primary explosives. The lead block test measures the expansion of a defined cavity, caused by detonation of a substance.

$\begin{array}{lccccc}\text { Substance } & \begin{array}{c}\text { Friction } \\ \text { sensitivity } \\ {[\mathrm{N}]}\end{array} & \begin{array}{c}\text { Impact } \\ \text { sensitivity } \\ {[\mathrm{Nm}]}\end{array} & \begin{array}{c}\text { Electrostatic } \\ \text { sensitivity } \\ {[\mathrm{mJ}]}\end{array} & \begin{array}{c}\text { Performance } \\ \text { lead block test } \\ {\left[\mathrm{cm}^{3} / 10 \mathrm{~g}\right]}\end{array} & \begin{array}{c}\text { Minimal } \\ \text { quantity to } \\ \text { initiate PETN }\end{array} \\ \begin{array}{l}\text { Mercury fulminate } \\ \text { Lead azide }\end{array} & 8 & 1-2 & 10 & 130 & 0.17 \mathrm{~g} \\ \text { Lead styphnate } & 8.1-1 \text { (pure) } & 2.5-4 & 0.4 & 110 & 0.02 \mathrm{~g} \\ \text { Tetrazene } & 8 & 2.5-5 & 1-10 & 130 & 0.55 \mathrm{~g}\end{array}$

expected for safety in handling and storage of the products.

\subsubsection{Production and Chemical Aspects}

Most of the substances used belong to the family of the aromatic nitro compounds, the aliphatic nitramines and the nitrate esters. They are produced by liquid-phase nitration with acid, a classical chemical procedure. For special compounds, used only in small quantities, syntheses in several steps and nitration with nitrous oxides are applied too. Byproducts, isomeric compounds and acid residues have to be removed to obtain a pure, stable and constant product. One example is crude 2,4,6-trinitrotoluene, which contains $2-5 \%$ of isomeric trinitro and dinitro compounds, whereas the demanded TNT purities in munitions production are in the range of 99-99.7\%. The technical conditions for the synthesis, cleaning, and refining procedures of the classical compounds are widely published [1][3]. In Table 2 the chemical data and impact sensitivity of commonly used energetic compounds are shown and in Fig. 2 the corresponding structures are presented.

For special applications a lot of other energetic compounds are used, e.g. 1,3,5-trinitrobenzene (TNB), 3,3bis(2, 2', 4, 4',6,6'-hexanitrostilbene) (HNS), 1,3,5-triamino-2,4,6-trinitrobenzene (TATB).

\subsubsection{Physical Properties}

The knowledge of the energetic and physical properties is important for the development of explosive charges with a defined performance. Table 3 shows the energetic data of commonly used energetic compounds. The optimization of the main goals, high performance when detonating, safety and low vulnerability are almost contradictory. The common practice of adding waxes and polymers to increase the stability reduces the performance of the energetic components.

\subsubsection{Trends and New Energetic Compounds}

Several known and many new energetic molecules were tested in regard of their potential for the new generation of insensitive high explosives (IHE). One of them is 3-nitro-1,2,4-triazol-5-one (NTO) (Fig. 3).

NTO is easy to prepare: In a first step the condensation of semicarbazid hydrochloride with formic acid leads to triazole and the second step is a conventional nitration. The resulting NTO is very insensitive and hard to set on fire. After initiation it has a high detonation velocity $(8590 \mathrm{~m} / \mathrm{s})$. Disadvantages are the high solubility in water, the acid reaction by hydrolysis and the 
<smiles>Cc1c([N+](=O)[O-])cc([N+](=O)[O-])cc1[N+](=O)[O-]</smiles>
TNT<smiles>O=[N+]([O-])N1CN([N+](=O)[O-])CN([N+](=O)[O-])C1</smiles>

Hexogen (RDX)<smiles>CN(c1c([N+](=O)[O-])cc([N+](=O)[O-])cc1[N+](=O)[O-])[N+](=O)[O-]</smiles>

Fig. 2. Structures of commonly used high explosives

Table 2. Chemical properties and impact sensitivity of high explosives

\begin{tabular}{|c|c|c|c|c|}
\hline Name of explosive & $\begin{array}{l}\text { Melting point } \\
{\left[{ }^{\circ} \mathrm{C}\right]}\end{array}$ & $\begin{array}{l}\text { Deflagration point } \\
\text { with } 20^{\circ} \mathrm{C} / \mathrm{min}\left[{ }^{\circ} \mathrm{C}\right]\end{array}$ & $\begin{array}{c}\text { Impact } \\
\text { sensitivity }[\mathrm{Nm}]\end{array}$ & $\begin{array}{l}\text { Density } \\
{\left[\mathrm{g} / \mathrm{cm}^{3}\right]}\end{array}$ \\
\hline TNT: 2,4,6-trinitrotoluene & 80.8 & 300 & $>20$ & 1.654 \\
\hline $\begin{array}{l}\text { PETN: pentaerythritol } \\
\text { tetranitrate }\end{array}$ & 141.3 & 202-205 & 2 & 1.770 \\
\hline $\begin{array}{l}\text { RDX, Hexogene: } \\
\text { Cyclotrimethylenetrinitramine }\end{array}$ & 204 decompos. & 230 & 4 & 1.820 \\
\hline $\begin{array}{l}\text { HMX, Octogen: } \\
\text { Cyclotetramethylenetetramine }\end{array}$ & 282 decompos. & 287 & 3 & 1.907 \\
\hline $\begin{array}{l}\text { Tetryl: } \\
\mathrm{N}, 2,4,6 \text {-tetranitroaniline }\end{array}$ & 129.4 & $185-195$ & 2 & 1.730 \\
\hline
\end{tabular}

Table 3. Energetic data from the armasuisse explosives database. The lead block test measures the expansion of a defined cavity, caused by detonation of a substance.

\begin{tabular}{lcccc} 
Name & $\begin{array}{c}\text { Heat of explosion } \\
{[\mathrm{kJ} / \mathrm{kg}]}\end{array}$ & $\begin{array}{c}\text { Detonation velocity } \\
{[\mathrm{m} / \mathrm{s}]}\end{array}$ & $\begin{array}{c}\text { Max. detonation } \\
\text { pressure }[\mathrm{GPa}]\end{array}$ & $\begin{array}{c}\text { Lead block test } \\
{\left[\mathrm{cm}^{3} / 10 \mathrm{~g}\right]}\end{array}$ \\
\hline TNT & 3.72 & 6900 & 22.3 & 300 \\
PETN & 6.31 & 8400 & 33.5 & 523 \\
RDX & 5.62 & 8750 & 34.1 & 480 \\
HMX & 5.60 & 9100 & 39.0 & 480 \\
Tetryl & 4.25 & 7850 & 26.9 & 410 \\
\end{tabular}

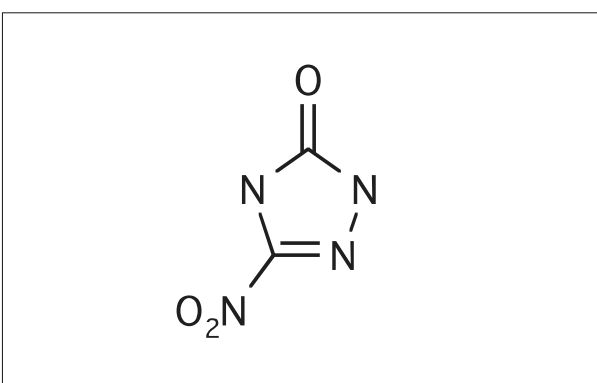

Fig. 3. Nitrotriazolone (NTO)

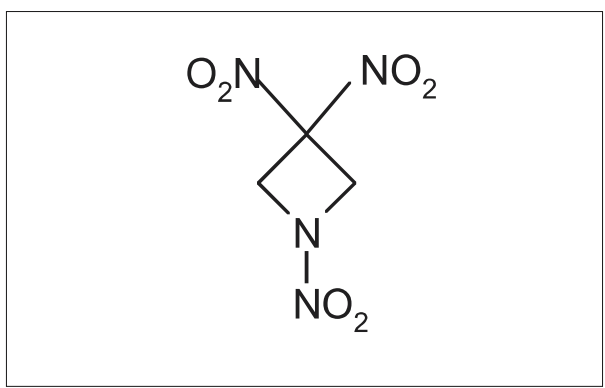

Fig. 4. Trinitroazetine (TNAZ)

large critical diameter needed for the continuation of the detonation.

1,3,3-trinitroazetine (TNAZ) (Fig. 4) is another new energetic and insensitive molecule. TNAZ has potential properties as an insensitive explosive. The low melting point allows its processing by melting. For its preparation seven steps are necessary and therefore production is very expensive.

Another compound with potential properties as an IHE is ammoniumdinitramide $\mathrm{NH}_{4} \mathrm{~N}\left(\mathrm{NO}_{2}\right)_{2}(\mathrm{ADN})$. This new substance has a good oxygen balance and contains much energy, but it is difficult to produce in a pure quality.

\subsubsection{Hexanitrohexaazaisowurtzitane as a Newcomer}

The new molecule 2,4,6,8,10,12-(hexanitro-hexaaza)-tetracyclododecane (HNIW or CL-20) is a nitramine compound, similar to RDX and HMX. HNIW has a high density $\left(2.04 \mathrm{~g} / \mathrm{cm}^{3}, \varepsilon\right.$-modification) and therefore a calculated [4] theoretical detonation velocity of $9400 \mathrm{~m} / \mathrm{s}$ which cannot be reached by any other organic explosive at the present time. Scheme 1 shows the synthesis of HNIW.

CL-20 was invented and synthesized by A.T. Nielsen [5] in 1989 at the US Navy test center China Lake, which is why the name 'CL' was selected. The synthesis needs three steps, as described in the patent of Nielsen [6]. In the first step the cage structure is formed by condensation of benzylamine with glyoxal. Then a partial debenzylation and an acylation are followed by reductive acylation in acetic anhydride. In the third step the debenzylation is complet- 

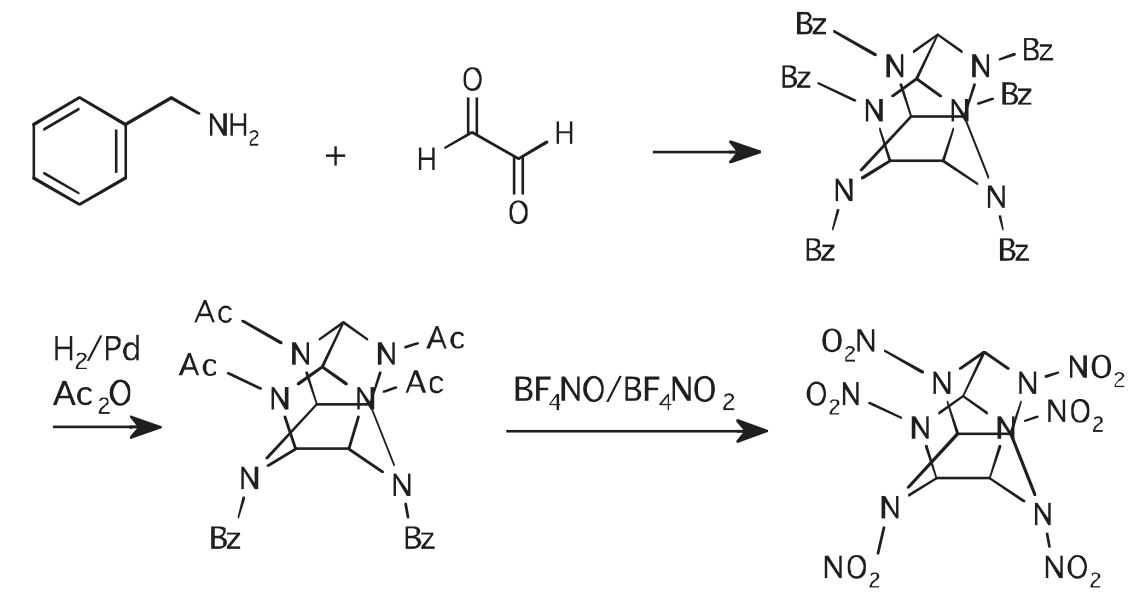

Scheme 1. The synthesis of HNIW/CL-20 in three steps

ed and a mild nitration by nitrosonium and nitronium tetrafluoroborate forms the nitramine groups.

In the industrial synthesis slightly modified processes have been established, in particular for the hydrogenolysis, described in the patent of R.B. Wardle [7]. A uncomplicated synthesis procedure, to produce large quantities of CL-20 at an acceptable price, is not available today.

Pure CL-20 is too sensitive for safe processing, handling, and storage. Mixtures with insensitive materials only or a surface coating of the CL-20 particles results in acceptable safety data. But the addition of insensitive substances reduces the performance of this material.

Another problem in using CL-20 is the polymorphism: the crystalline CL-20 can form six different modifications. Normally CL-20 exists in the $\varepsilon$-modification, which is thermodynamically stable at room temperature. Processing this material at elevated temperatures and high pressures facilitates a transformation to the less stable $\gamma$ - or other modifications. The polymer binder used, which is in contact with the surface of the CL-20 crystals, influences these transformations. A process control is necessary to be certain that no unstable modifications are formed. Using IR spectroscopy, the different modifications can be distinguished by the control of the peaks in the finger print region in the spectra [8].

CL-20 has the potential to be used in the future for explosive charges for highest performance and as an energetic additive in rocket propellants, but the material is still too expensive for common use.

\subsection{Binder Systems}

Basically, the selection of the binder system determines the processing technology of an explosive. By coating or mixing the crystalline energetic compound with a binder system, the formulation is desensitized. During processing, in the curing stage, the formation of a solid binder matrix is achieved. The type of binder significantly influences the mechanical properties and consequently the vulnerability of the explosive charges. A possible further addition of bonding agents and plasticizers allows a systematic modification of the characteristics of the binder. The development of new, less sensitive explosive formulations is mainly achieved by technical innovations in polymeric binder systems. Below an overview of the different binder types and of current trends in this area is given.

\subsubsection{Energetic Compounds with a Low Melting-point}

For castable explosives energetic compounds with low melting points (70 to 110 ${ }^{\circ} \mathrm{C}$ ) are used directly as binders. The condition for the use of an energetic compound for this purpose is a sufficient separation between melting point and start of the chemical decomposition reaction. Pure TNT melts at $80.8^{\circ} \mathrm{C}$; however the thermal decomposition does not start before $290^{\circ} \mathrm{C}$. In charges consisting of homogeneous TNT only, TNT acts as an energetic compound and as a binder. In addition, e.g. in mixtures with up to $80 \%$ insoluble energetic compounds of high performance like hexogen (hextro formulations) and octogen (octol formulations), TNT has the function of a binder.

Cast charges based on TNT as binder do not meet today's criteria for insensitive ammunition. Alternatives for TNT were sought. These alternative substances must allow the production of charges with conventional casting facilities and also meet the criteria for active components in insensitive ammunition. The development of a new series of explosives by the US Army is worth watching closely. It is based on the binder 2,4 dinitroanisol (DNAN) [9] which is a yellow crystalline substance at room temperature and has a melting point of 94.5 ${ }^{\circ} \mathrm{C}$.

\subsubsection{Plastics}

Until the 1960s mainly waxes and paraffins were used as classic binder systems for pressed explosive formulations. In modern pressed and diecast formulations, particularly in the field of insensitive high explosives (IHE), mainly polymers are used due to their wide range of properties. The development goes back to the 1950s, when in the formulation of pressed explosives mainly thermoplastics were used, which were known from civilian applications (e.g. nylon, Teflon, polyisobutylene). However, the mechanical properties of most of the respective formulations showed undesirable hardness, which has a negative effect on the sensitivity. Therefore elastomers (rubber), with hardness from soft to stiff and elongation of up to $400 \%$, are being increasingly used in modern formulations. From the 1960s onwards, the development and availability of tailored resin/hardener systems led to the introduction of the 'cast-cure' technology. Today the used polymers are often matched to their specific application in the formulation of explosives. A novel energetic binder system containing nitro or acido groups is now available. The mechanical properties of this binder system can be controlled by means of the selective arrangement of hard and soft block segments.

\subsubsection{Plastic Binders for Pressed Formulations}

Mainly thermoplastics and elastomers are used as binders for pressed formulations. The granulates used to manufacture the pressed charges consist of surface-coated (each crystal is individually coated with a thin polymer film) crystalline energetic compounds.

The distinction between thermoplastics and elastomers is not totally clear in every case. In the field of pressed explosives almost exclusively non-branched polymers are used, which are defined as thermoplastics. However, there are a number of polymers which are partly hardened or originate from the family of block-co-polymers and therefore show very high molecular weights or very long chains. In this case the mobility of the chains is limited and the behavior corresponds more to that of an elastomer. We will subsequently define the type of binder polymer based on the behavior and not on the degree of cross linking.

As the following examples will show, polymers with very different chemical origins are used in explosive formulations. 
<smiles>CCCCCCOC(=O)CCCCC(=O)OCCCCCCCCOC(=O)Nc1cccc(Cc2ccc(N=C=O)cc2)c1</smiles>

estane: 1,4-butandiol-adipate, with MDI cross-linked to polyurethane

Fig. 5. Structure of ESTANE [10]

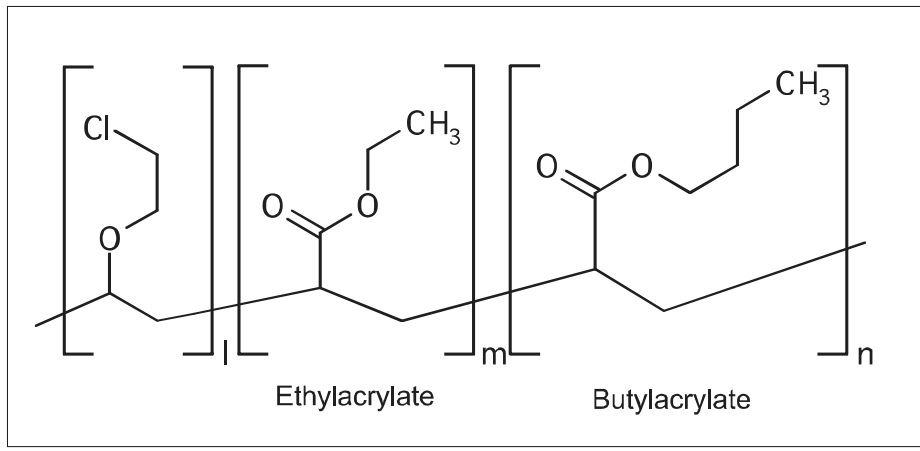

Fig. 6. Structure of HYTEMP

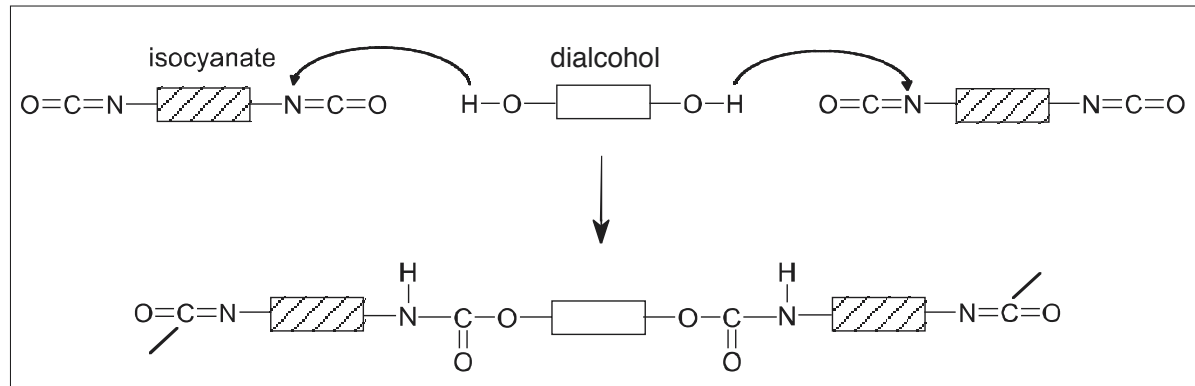

Scheme 2. Crosslinking of polyurethanes

ESTANE (Fig. 5), for example, is a polyester with an $\mathrm{OH}$ group on the end of the chain, whose free alcohol functionality is cross-linked to a polyurethane with an isocyanate (4,4'-diisocyanatdiphenylmethan). ESTANE is a classical binder which is commercially used in the formulation LX-14. Based on the distinct thermoplastic behavior of ESTANE (softening starts at $50{ }^{\circ} \mathrm{C}$ ) the respective formulations are processed under elevated temperature conditions $\left(90-110^{\circ} \mathrm{C}\right)$. Depending on the chain structure, such polyurethanes show very different mechanical properties. The esterification with tri- and tetra-alcohols can be used to achieve additional cross linking. In hot water or water vapor atmosphere, the polymer decomposes through hydrolysis.

HYTEMP (Fig. 6) is another binder based on an ethyl-/butylacryl-co-polymer. It contains a small percentage of chloric monomers, mostly 2-chlor-ethylvinylether, which are used for cross linking. The acrylic elastomer is resistant to ageing, heat and fatigue. Moreover HYTEMP is resistant to oxygen, ozone, oil and UV light; its stability in hot water and water vapor is under certain conditions only just sufficient. Most formulations based on HYTEMP contain the softening agent dioctyladipat (DOA), which is added in a ratio of 1:3 $(\mathrm{w} / \mathrm{w})$. Particularly if the percentage of binder is high, the explosive has a soft and crumbling consistency. This makes the mechanical processing of the respective charges very difficult.

In addition fluorinated co-polymers and silicone rubbers are also used as binders.

\subsubsection{Plastic Binders for 'Cast-cure' Formulations}

Plastics which are used as binders for the cast-cure technology of explosives are based on resin/hardener systems. The formulation is homogenized in a mixer, filled into a mould or case and then cured at elevated temperature. The main group of 'cast-cure' binders includes cureable polyurethanes. The basis for the crosslinkage reaction are hydroxyl terminated polymers, which can be cross linked with isocyanates. Scheme 2 shows the schematic description of the crosslinkage process.

Depending on the functionality of the alcohol and isocyanate used (di-, tri-, tetrafunctional) the degree of crosslinking and hence the mechanical properties can be controlled. This fact, together with the multitude of basic substances (polyols), makes it possible to create 'made-to-measure binder systems'.

Among the so-called crosslinkable polyether prepolymers there are both inert and energetic representatives. While in today's classical formulations mainly polyethylene glycol or polypropylene glycol is used, polymers used in the future will be modified with energetic groups in the molecule. The filling capacity of diecast explosives is limited by the viscosity of the explosive mass to be processed. The relatively high percentage of binder material $(>10 \%)$ leads to a reduced performance. In order to partially compensate for this, energetic prepolymers were developed. Due to their $\mathrm{OH}$ groups on the end of the chain, they can be crosslinked to polyurethans by means of isocyanates too. Moreover, there is the possibility of producing energetic block-co-polymers from such prepolymers, consisting of hard and soft segments, reaching comparable mechanical properties to the thermoplastic elastomers (TPE).

The type of the soft segment influences the glass transition temperature of the polymer, the hard segment influences the melting temperature. By combining hard and soft segments (type, distribution of molecular weight, arrangement of segments) the properties of these binder systems can be controlled and adjusted to the specific needs [11].

Thermoplastic elastomers are processed at higher temperature than crosslinked polymers (pressed, extruded etc.). During processing at higher temperatures the thermoplastic elastomer forms a liquid film which embeds the energetic compounds. After cooling down, a solid energetic charge is obtained. The mechanical properties are comparable to a product manufactured with a crosslinked polymer. The best known energetic thermoplastic elastomers used today are based on a block-copolymer consisting of 3-azidomethyl-3methyloxetan (AMMO) and poly[3,3bis(azidomethyl)oxetan) (BAMO) segments (Fig. 7) [12].

In the field of crosslinked polymers GAP (glicidyl-acid polymer) (Fig. 8) is becoming increasingly important for many applications.

Hydroxyl terminated polybutadienes (HTPB) (Fig. 9) cannot be fitted into the 


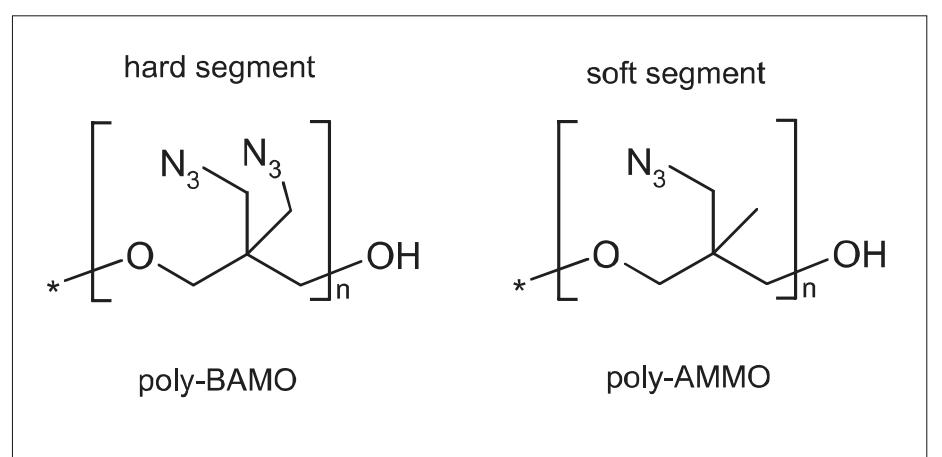

Fig. 7. Example of typical prepolymers which are used as hard and soft segments

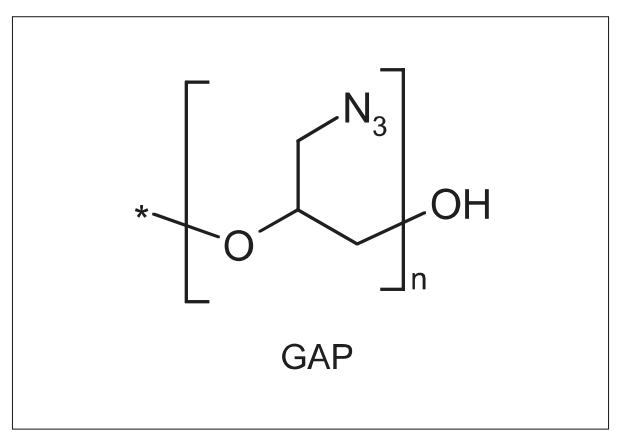

Fig. 8. Glicidyl-acid-polymer

system of cross-linkable polyesters and polyethers. Due to the outstanding mechanical properties of HTPBs, they have been used in the field of explosives since 1989 as crosslinkable prepolymers. Several commercial available explosives are qualified with HTPB in the formulation.

The very high elasticity has a shock-absorbing effect which drastically reduces the sensitivity of the respective explosive. A high percentage of 1,4-crosslinkages with cis-double bonds has a positive effect on elasticity and lowers the glass transition temperature. 1,2-crosslinkages have the opposite effect. The use of a HTPB is also foreseen for modern diecast explosives on the basis of CL-20.

The curing agents used for crosslinking hydroxyl terminated polymers are di- or triisocyanates. The degree of crosslinkage can be controlled by means of the functionality. The isocyanates used most frequently in explosives are isophorondiisocyanate (IPDI) and 4,4'-diisocyanatdiphenylmethane (MDI) (Fig. 10).

In order to accelerate the crosslinking of resin and curing agent systems, cure catalysts are used. For polyurethanes primarily metallo-organic tin compounds are used for this purpose.

\subsection{Additives}

\subsubsection{Addition of Plasticizers}

By adding plasticizers, the mechanical properties of binder systems can be adjustpolymers

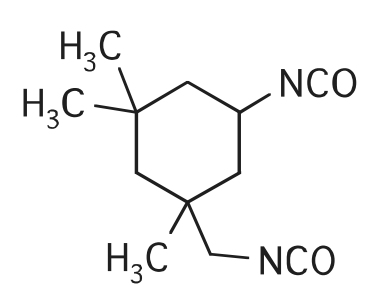

Isophorondiisocyanate

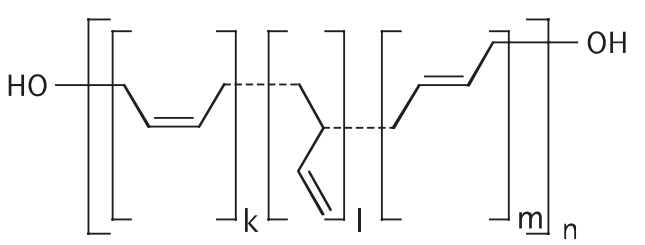

for R45M:

$\mathrm{k}=0.2$

$\mathrm{I}=0.2$

$\mathrm{m}=0.6$

$\mathrm{n}=50$

Fig. 10. Typical diisocyanate curing agents for the 'cast-cure' process of hydroxyl terminated pre-<smiles>O=[N+]([O-])c1ccc(Cc2ccc([N+](=O)[O-])cc2)cc1</smiles>

4,4'-Diisocynatdiphenylmethane ed within a wide range. Plasticizers reduce the auxiliary valency forces between the polymer chains of a rigid crystallite structure and thereby soften it. The miscibility, compatibility, and migration stability of a plasticizer within a polymer matrix is an absolute prerequisite for its applicability.

Typical representatives of low viscosity monomer plasticizers are dioctyl adipate in HYTEMP and isodecyl pelargonat in HTPB-polyurethane. But there are also energetic plasticizers such as bis(2-fluor-2,2dinitroethyl)formal (FEFO) or bis(2,2-dinitropropyl)acetal/formal (BDNPA/F) (Fig. 11).

\subsubsection{Other Additives}

To meet requirements, the properties of an explosive formulation can be modified by adding different additives.

To improve the adhesion between the crystals of the energetic compound and the surrounding binder, metal-organic compounds based on titanium are used as 'bonding agent' in several explosives. N,N 2-Hydroxyethyl-dimethyl-hydantion (Dantocol) is also widely used as a bonding agent.

Polymers, elastomers, thermoplastic elastomers and in particular energetic polymers and plasticizers have to be protected from ageing and degradation with adequate stabilizers as e.g. strongly sterically hindered bisphenyl.

\subsection{Performance}

The performance of an explosive formulation largely depends on the type and filling capacity of the energetic compound and, if energetic binders are used, on the energy they contribute to the conversion reaction. Since the performance depends directly on the energy density, there is a linear increase of detonation velocity and detonation pressure as the density of the formulation increases.

The main parameters used to determine the performance of military explosives are: detonation velocity, detonation pressure and the resulting capability to accelerate metals. These parameters can be determined experimentally or calculated by means of suitable computer codes. In Table 4 the performance data of some common military explosive formulations are listed.

At the moment formulations based on octogen offer the highest performance potential (see Table 4). By developing formulations containing the new energetic compound CL20 , the performance of future explosive charges can be increased by $10-15 \%$. For the first time the extraordinarily high detonation velocity of $9280 \mathrm{~m} / \mathrm{s}$ was measured in a formulation consisting of $98 \%$ CL-20 and $2 \%$ of the energetic polymer GAP [14]. Fig. 12 shows the detonation velocity versus density curve of new high explosive formulations containing the energetic polymer GAP.

Received: March 30, 2004 
Table 4. Performance data of military explosive formulations

\begin{tabular}{|c|c|c|c|c|c|}
\hline Name & $\begin{array}{l}\text { Composition } \\
\text { [\% by weight] }\end{array}$ & $\begin{array}{l}\text { Density } \\
{[\mathrm{g} / \mathrm{ccm}]}\end{array}$ & $\begin{array}{l}\text { Detonation } \\
{[\mathrm{m} / \mathrm{s}]}\end{array}$ & $\begin{array}{c}\text { Pressure } \\
\text { [GPa] }\end{array}$ & Processing \\
\hline Comp A3 & $\begin{array}{c}\text { Hexogen/Wax } \\
91 / 9\end{array}$ & 1.67 & 8520 & 26.0 & \multirow{3}{*}{$\begin{array}{l}\text { రू } \\
\mathscr{D} \\
W \\
0 \\
0\end{array}$} \\
\hline LX-14 & $\begin{array}{l}\text { Octogen/Estane } \\
\quad 95.5 / 4.5\end{array}$ & 1.81 & 8830 & 37.0 & \\
\hline PBXW-11 & $\begin{array}{c}\text { Octogen/Hytemp/DOA } \\
96 / 1 / 3\end{array}$ & 1.79 & 8690 & 29.1 & \\
\hline PAX 21 & $\begin{array}{c}\text { DNAN/Ammonium } \\
\text { perchlorate/Hexogen } \\
34 / 30 / 36\end{array}$ & 1.73 & 8120 & 29.1 & \multirow[b]{2}{*}{ 芴 } \\
\hline Composition B & $\begin{array}{c}\text { original blend TNT/ } \\
\text { Hexogen/Wax } \\
39.5 / 59.5 / 1\end{array}$ & 1.72 & 7920 & 29.2 & \\
\hline Octol & $\begin{array}{l}\text { original blend TNT/ } \\
\text { Octogen } 75 / 25\end{array}$ & 1.76 & 8300 & 31.6 & \multirow{3}{*}{$\begin{array}{l}\bar{n} \\
\tilde{D} \\
\dot{d} \\
\dot{\alpha}\end{array}$} \\
\hline PBXN-109 & $\begin{array}{c}\text { Hexogen/Al/HTPB } \\
64 / 20 / 16\end{array}$ & 1.70 & 7480 & 23.4 & \\
\hline PBXN-110 & $\begin{array}{c}\text { Octogen/HTPB } \\
88 / 12\end{array}$ & 1.68 & 8390 & 29.1 & \\
\hline
\end{tabular}

$\overbrace{\mathrm{NO}_{2}}^{\mathrm{NO}_{2}} \mathrm{~N}_{\mathrm{NO}_{2}}^{\mathrm{NO}_{2}}$

FEFO

$\mathrm{R}=\mathrm{CH}_{3}: \operatorname{BDNPA}(50 \%)$
$\mathrm{R}=\mathrm{H}: \quad \operatorname{BDNPF}(50 \%)$

Fig. 11. Energetic plasticizers

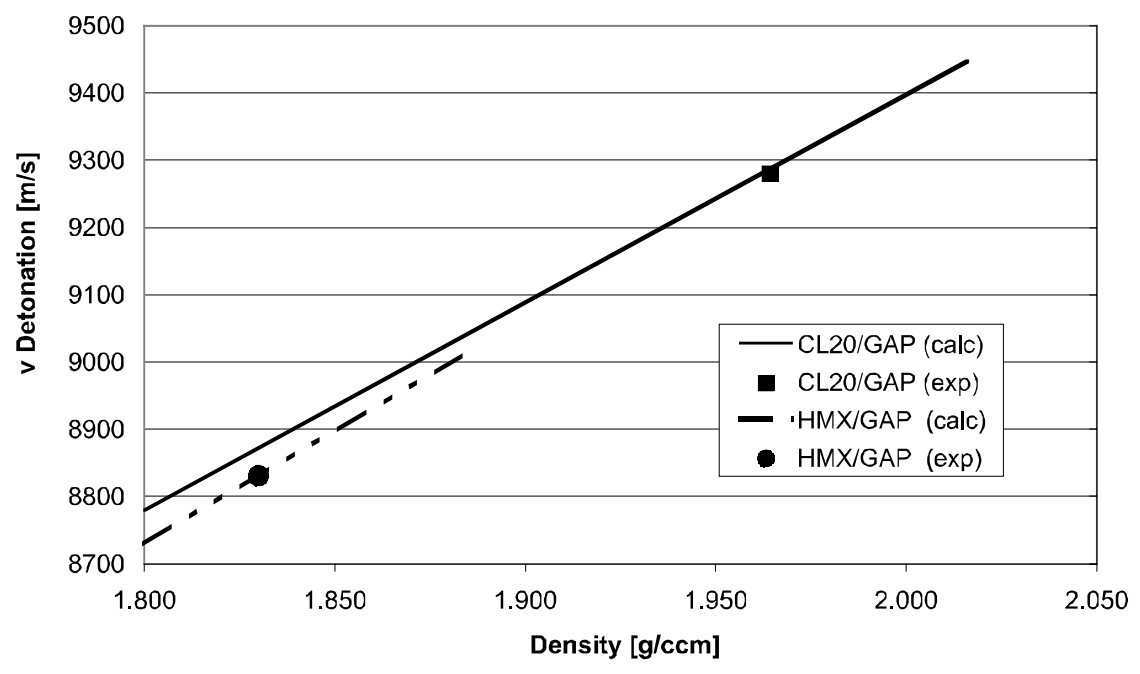

[1] J. Köhler, R. Meyer, 'Explosivstoffe', Wiley-VCH, D-Weinheim, D, 9. Auflage, 1998.

[2] U. Brede, R. Hagel, K.H. Redecker, W. Weuter, 'Primer Compositions in the Course of Time: From Black Powder and SINOXID to SINTOX Compositions and SINCO Booster', Propellants, Explosives, Pyrotechnics, 1996, 21, 113-117.

[3] Ullmann's Encyclopedia of Industrial Chemistry, Vol. A10, 1987.

[4] H. Schubert, 'Explosivstoffe für militärische Anwendungen', Spektrum der Wissenschaft, August 1996, pp. 97-101.

[5] A.T. Nielsen, 'Polycyclic Amine Chemistry', in 'Chemistry of Energetic Materials', Eds. G.A. Olah, R.D. Squire, Academic Press, San Diego, 1991, pp. 95-124.

[6] A.T. Nielsen, US-Patent Nr. 5,693,794, 1997.

[7] R.B. Wardle, International Application WO 97/20785, PCT/US96/19130, 1997.

[8] J.H. Kim, Y.C. Park, Y.J. Yim, J.S. Han, 'Crystallization Behaviour of Hexanitrohexaazaisowurtzitane at $298 \mathrm{~K}$ and Quantitative Analysis of Mixtures of its Polymorphs by FTIR', J. Chem. Eng. Japan, 1998, 31/3, 478-481.

[9] S. Nicolich, J. Niles, D. Doll, M. Ray, M. Gunger, A. Spencer, 'Development of a Novel High Fragmentation/High Blast Melt Pour Explosive', Proceedings IM\&EM Symposium, Orlando, USA, 2003.

[10] B.M. Dobratz, P.C. Crawford, 'LLNL Explosives Handbook', Lawrence Livermore National Laboratory, Livermore CA, USA, 1985.

[11] Courseware, 'Einführungskurs Polymerchemie und Polymertechnologie', Ecole d'ingénieurs du Valais, Sion, $\mathrm{CH}$, 1997.

[12] J. Hamid, C.J. Wyres, R.M. Endsor, P.E. Brough, 'Recent Advances in Energetic Binder Synthesis', Proceedings IM\&EM Symposium, Orlando, USA, 2003.

[13] P. Wanninger, 'PBX Charges of the Third Generation', Proceedings IM\&EM Symposium, Orlando, USA, 2003.

[14] J. Mathieu, P. Mäder, B. Berger, H.R. Bircher, 'CL-20 based formulation for high performance warhead application', Proceedings IM\&EM Symposium, Tampa, USA, 1999, p. 141.

Fig. 12. Calculated and measured detonation velocity of CL-20/GAP 98/2 compared to HMX/GAP $98 / 2$ 